\title{
The profile of alkali-soluble phenolic acids in maize stover, and rice and wheat straws*
}

\author{
H. Zhang, Q.X. Meng, Z.M. Zhou, C.M. Sun and L.P. Ren ${ }^{1}$ \\ State Key Laboratory of Animal Nutrition, College of Animal Sciences \& Technology, \\ China Agricultural University \\ Beijing 100094, P.R. China
}

\begin{abstract}
Nine alkali-soluble phenolic acids (gallic acid, protocatechuic acid, p-hydroxybenzoic acid, vanillic acid, caffeic acid, syringic acid, trans-p-coumaric acid, trans-ferulic acid, sinapic acid) in maize stover, and rice and wheat straws were determined by HPLC after alkaline hydrolysis. The most abundant amount of total alkali-soluble phenolic acids was detected in maize stover, followed by rice straw and wheat straw, accounting for, \%: 1.23, 1.21 and 0.87 on DM basis, respectively. Trans-p-coumaric acid and trans-ferulic acid were the preponderant phenolic acids in all three kinds of crop residues studied. Nine phenolic acids were found to be present in CAU 108 maize stover, but protocatechuic acid, p-hydroxybenzoic acid and caffeic acid were not detected in rice and wheat straws.
\end{abstract}

KEY WORDS: phenolic acids, HPLC, maize stover, rice straw, wheat straw

\section{INTRODUCTION}

Crop residues are important animal feeds in many developing countries. Up to $80 \%$ of their dry matter is cell-wall polysaccharides. The utilization of energy source depends on both the physical properties and the chemical composition of it. Phenolic acids are plant metabolites widely spread throughout the plant kingdom. Researchers observed that phenolic acids have many negative effects on ruminant animals, such as inhibiting coarse fodder digestion, influencing attachment of the fibrolytic microorganisms to fibre particles (Varel and Jung, 1986), having

\footnotetext{
* Supported by National Outstanding Young Scientist Foundation, Grant No. 30125033 and National Natural Science Foundation of China, Grant No. 30270944

${ }^{1}$ Corresponding author: e-mail: renlp@cau.edu.cn
} 
poison to the rumen micro-organisms (Chesson et al., 1982) and influencing rumen microbial growth (Borneman et al., 1986). Maize stover, rice straw and wheat straw are important roughage sources of ruminants in China. However, the information about the kind and the amount of phenolic acids present in maize stover, rice straw and wheat straw is lacking. Therefore, the objective of this study was to investigate the profile of alkali-soluble phenolic acids in maize stover, rice straw and wheat straw.

\section{MATERIAL AND METHODS}

Maize stover (CAU 108), rice straw and wheat straw were obtained from the Experimental Station of China Agricultural University (Dongbeiwang area, Beijing), dried under sunlight and then ground (Perten Laboratory Mill 3100, $2700 \mathrm{rpm}$ ) to pass a $1.5 \mathrm{~mm}$ size screen. Then, they were dewaxed with ether in a Soxhlet apparatus for $12 \mathrm{~h}$. All reference chemicals were purchased from Acros Company except for p-hydroxybenzoic acid and gallic acid, which are from Beijing Chemical Reagents Company, Beijing.

Alkali-soluble phenolic acids were analysed according to the methods described by Mattila et al. (2005) and Xu et al. (2005) with minor modifications. Namely, the dewaxed samples $(0.025 \mathrm{~g} \mathrm{DM})$ were treated with thermostable $\alpha$-amylase (Sigma, A3306) for $15 \mathrm{~min}$, and then saponified with $10 \mathrm{ml}$ of $4 \mathrm{M} \mathrm{NaOH}$ for 2 $\mathrm{h}$ at $100^{\circ} \mathrm{C}$. The residue was filtered off and washed with water. The filtrate was neutralized to $\mathrm{pH}<2.0$ with $6 \mathrm{M} \mathrm{HCl}$ and extracted with chloroform $(30 \mathrm{ml} \times 3)$. The chloroform extracts were combined and evaporated under reduced pressure and $40^{\circ} \mathrm{C}$ in a rotor-evaporator (RE-52 AA, Shanghai, China) until dryness and then re-dissolved in $2 \mathrm{ml}$ methanol (Fisher), membrane filtered prior to HPLC analysis.

Alkali-soluble phenolic acids were analysed by HPLC (Model 1100, Agilent) on a SB-C $18(4.6 \mathrm{~mm} \times 150 \mathrm{~mm} \times 3.5 \mu \mathrm{m}$, Agilent $)$ column at room temperature. Elution was carried out using a linear gradient system consisting of solvent A (water: methanol: acetic acid $=89: 10: 1$ ) and solvent B (methanol: water: acetic acid =90:9:1). Run over 28 min from 0 to $40 \% \mathrm{~B}$ at a flow rate of 1 $\mathrm{ml} / \mathrm{min}$. The injection volume was $20 \mu \mathrm{l}$. Quantitative data were obtained from the chromatograms recorded at $280 \mathrm{~nm}$ with an ultraviolet monitor. Phenolic acids were identified by comparison of their relative retention times with those of standard compounds and quantified using external reference method. All sample treatment process and analysis were protected from light.

All data were subjected to analysis by one-way GLM procedure of SAS (version 8.0) software, and the multiple comparisons of the data were performed using Duncan's new multiple range method. 


\section{RESULTS AND DISCUSSION}

As described by Sun et al. (2001), only parts of ester-linked and ether-linked phenolic profiles were obtained by traditional alkali and acid hydrolysis. As a result, strong base and high temperature condition was used to release total ester-linked and ether-linked phenolic acids in this study. The interference of the background was considerably reduced with addition of thermostable $\alpha$-amylase. Nine phenolic acids were well separated and detected with the optimized HPLC method. The recovery, linearity range and correlation coefficient were satisfactory.

The contents of alkali-soluble phenolic acids in three different roughages were determined and shown in Table 1 . The highest contents $\left(1.23 \times 10^{4} \mu \mathrm{g} / \mathrm{g} \mathrm{DM}\right)$ of total alkali-soluble phenolic acids were in maize stover, followed by rice straw $\left(1.17 \times 10^{4} \mu \mathrm{g} / \mathrm{g} \mathrm{DM}\right)$ and wheat straw $\left(8.74 \times 10^{3} \mu \mathrm{g} / \mathrm{g} \mathrm{DM}\right)$. The results indicated that the amount of total alkali-soluble phenolic acids varied very much between plant species. This observation was in good agreement with the study on the content of phenolic acids in rye grass (Andreasen et al., 2000).

Table 1. Contents of alkali-soluble phenolic acids in maize stover, rice straw and wheat straw

\begin{tabular}{lcllllr}
\hline \multirow{2}{*}{ Phenolic acid } & \multicolumn{3}{c}{ Contents, $\mu \mathrm{g} / \mathrm{g} \mathrm{DM}^{1}$} & \multirow{2}{*}{ SEM } & P \\
\cline { 2 - 5 } & maize stover & rice straw & wheat straw & & \\
\hline Gallic acid, GA & 20.6 & nd & nd & 0.605 & $<0.0001$ \\
Protocatechuic acid, PRA & $1.24 \times 10^{3}$ & $2.68 \times 10^{3}$ & $7.61 \times 10^{2}$ & 107 & $<0.0001$ \\
p-Hydroxybenzoic acid, PHBA & $1.04 \times 10^{2}$ & nd & nd & 0.698 & $<0.0001$ \\
Vanillic acid, VA & $1.35 \times 10^{3}$ & $1.22 \times 10^{3}$ & $1.07 \times 10^{3}$ & 123 & 0.2970 \\
Caffeic acid, CA & 29.3 & nd & nd & 0.475 & $<0.0001$ \\
Syringic acid, SYA & $4.59 \times 10^{2}$ & $4.37 \times 10^{2}$ & $6.47 \times 10^{2}$ & 26.3 & 0.0006 \\
p-Coumaric acid, PCA & $4.80 \times 10^{3}$ & $3.03 \times 10^{3}$ & $3.41 \times 10^{3}$ & 108 & $<0.0001$ \\
Ferulic acid, FA & $3.71 \times 10^{3}$ & $3.97 \times 10^{3}$ & $2.71 \times 10^{3}$ & 108 & 0.0002 \\
Sinapic acid, SA & $5.70 \times 10^{2}$ & $3.59 \times 10^{2}$ & $1.41 \times 10^{2}$ & 22.8 & $<0.0001$ \\
Total & $1.23 \times 10^{4}$ & $1.17 \times 10^{4}$ & $8.74 \times 10^{3}$ & & \\
PCA/FA & 1.30 & 0.820 & 1.25 & & \\
\hline
\end{tabular}

${ }^{1}$ means of triplicated analyses are given with three significant digits nd - not detected

SEM - standard error of means

Large differences of kind and amount of phenolic acids in maize stover, and rice and wheat straws were observed. All the phenolic acids involved in this study were detected in maize stover, but only six phenolic acids (PRA, VA, SYA, PCA, FA and SA) were found in rice straw and wheat straw. GA, PHBA and CA were only detected in maize stover with a lower amount. There was a remarked difference in amount of alkali-soluble phenolic acids among the three crop residues $(\mathrm{P}<0.0001)$, with the exception of $\mathrm{CA}(\mathrm{P}=0.2970)$. 
$t$-PCA and $t$-FA were the most abundant phenolic acids in three crop residues studied, and the total amount of $t$-PCA and $t$-FA accounted for, \%: 69.31, 58.86 and 70.02 of total phenolic acids in maize stover, rice straw and wheat straw, respectively. The ratio of PCA to FA was the highest in maize stover, followed by wheat straw, and then the lowest in rice straw. It has been reported that the concentrations of PCA and the ratio of PCA to FA had a negative effect on cell wall digestibility (Hartley, 1972). However, Casler and Jung (2006) reported negative effects of esterified FA on in vitro $24 \mathrm{~h}$ neutral detergent fibre digestibility of smooth bromegrass and reed canarygrass, but the relationship was changed to positive values when digestibility was measured at $96 \mathrm{~h}$. Therefore, maize stover and wheat straw as roughages to be digested would need more time.

In addition to PCA and FA, some others of phenolic acids were also detected in the three crop residues, indicating that these related phenolic acids may take the formation of ester- and ether bond between lignin and polyoses, or between lignin fragments. More evidence showed that PHBA bond to lignin (Sun et al., 1999), and GA monomer and tripolymer bond to glucose of soluble tannin (Clifford and Scalbert, 2000).

\section{CONCLUSIONS}

The content of total alkali-soluble phenolic acids was detected in the decreased order: maize stover $(1.23 \%)<$ rice straw $(1.21 \%)<$ wheat straw $(0.87 \%)$, respectively. p-coumaric acid and protocatechuic acid were the commonly detected phenolic acids with the relatively high contents in the three roughages. All nine phenolic acids were detected in maize stover, while protocatechuic acid, p-hydroxybenzoic acid and caffeic acid were never detected in rice and wheat straws. The ratio of p-coumaric acid to ferulic acid was the highest in maize stover, followed by wheat straw, and then the lowest in rice straw.

\section{REFERENCES}

Andreasen M.F., Christensen L.P., Meyer A.S., Hansen A., 2000. Content of phenlic acids and ferulic acid dehydrodimers in 17 rye (Secale cereale L.) varieties. J. Agr. Food Chem. 48, 2837-2842

Borneman W.S., Akin D.E., WanEseltine W.P., 1986. Effect of phenolic monomers on ruminal bacteria. Appl. Environ. Microbiol. 52, 1331-1339

Casler M.D., Jung H.G., 2006. Relationships of fibre, lignin, and phenolics to in vitro fibre digestibility in three perennial grasses. Anim. Feed Sci. Tech. 125, 151-161

Chesson A., Stewart C.S., Wallace R.J., 1982. Influence of plant phenolic acids on growth and cellulolytic activity of rumen bacteria. Appl. Environ. Microbiol. 44, 597-603

Clifford M.N., Scalbert A., 2000. Ellagitannins-nature, occurrence and dietary burden. J. Sci. Food Agr. 80, 1118-1125 
Gabrielson B.C., Vogel K.P., Anderson B.E., Ward J.K., 1990. Alkali-labile cell-wall phenolics and forage quality in switch grass selected for differing digestibility. Crop Sci. 30, 1313-1320

Hartley R.D., 1972. p-Coumaric and ferulic acid components of cell walls of ryegrass and their relationships with lignin and digestibility. J. Sci. Food Agr. 23, 1347-1354

Mattila P., Pihlava J.M., Hellstrom J., 2005. Contents of phenolic acids, alkyl- and alkenylresorcinols, and avenanthramides in commercial grain products. J. Agr. Food Chem. 53, 8290-8295

Sun R.C., Sun X.F., Zhang S.H., 2001. Quantitative determination of hydroxycinnamic acids in wheat, rice, rye, and barley straws, maize stems, oil palm frond fiber, and past-growing poplar wood. J. Agr. Food Chem. 49, 5122-5129

Sun R.C., Tomkinson J., Bolton J., 1999. Separation and characterization of lignins from the black liquor of oil palm trunk fibre pulping. Separ. Sci. Technol. 34, 3045-3058

Varel V.H., Jung H.G., 1986. Influence of forage phenolics on ruminal fibrolytic bacteria and in vitro fiber degradation. Appl. Environ. Microbiol. 52, 275-280

Xu F., Sun R.C., Sun J.X., Liu C.F., He B.H., Fan J.S., 2005. Determination of cell wall ferulic and p-coumaric acids in sugarcane bagasse. Anal. Chim. Acta 552, 207-217 